\title{
DESENHOS DAS AVENTURAS QUIXOTESCAS: UM ESTUDO DA LITERATURA CERVANTINA ATRAVÉS DAS ILUSTRAÇÕES DE GUSTAVE DORÉ.
}

Wilton Alves Ferreira Júnior'; Antônio Wilson Silva de Souza ${ }^{2}$

1. Bolsista PIBIC/CNPq, Graduando em Licenciatura em História, Universidade Estadual de Feira de Santana, email: wfjr.alves@gmail.com

2. Orientador, Departamento de Letras e Artes, Universidade Estadual de Feira de Santana, e-mail: antoniowilsonsilv@gmail.com

PALAVRAS-CHAVE: Desenho; Ilustração; Literatura.

\section{INTRODUÇÃO}

A imagem faz parte de todas as experiências humanas, se esta é uma experiência que toca só aos seres humanos ainda é uma questão, mas na nossa experiência ela tem um papel centrar assim como outras formas de relação social, o poder, a identidade, etc. Essa consideração nos leva a alguns paradoxos interessantes, quando pensamos como academia tem tratado a imagem ao longo do tempo, sobre a competição entre os enunciados textuais e visuais.

$\mathrm{Na}$ academia ainda é muito comum que os historiadores usem as imagens reduzindo-as à uma função figurativa, noutras vezes as imagens são usadas para ilustrar conclusões que o autor já havia chegado por outros meios, uma espécie de "carimbo da verdade" (algo que precisa ser prontamente desmistificado). As razões para esta subutilização são muito variadas, sendo a mais comum delas a ausência de um letramento imagético, que restringe ao pesquisador das ferramentas metodológicas e conceituais necessárias para um trabalho competente com imagens. $\mathrm{O}$ enraizamento de uma cultura bacharelesca ligada essencialmente ao texto verbal, institui que passemos grande parte do tempo sendo letrados na leitura exclusiva de textos verbais, tanto no nível da educação básica quanto no ensino superior.

Ao transformar o discurso verbal em visual, o ilustrador indica novas possibilidades de conhecer, interpretar e ultrapassar o texto ampliando a experiência imersiva, para além da rigidez da palavra, oferecendo à imaginação do leitor novas espacialidades, expressões e sentidos, com as quais ele pode construir sua própria narrativa

\section{MATERIAL E MÉTODOS OU METODOLOGIA}

A metodologia de trabalho aplicada nessa pesquisa foi estabelecida pensando uma conjunção entre o método iconográfico iconológico proposto por Panofisky parte do princípio de que a atividade artística tem impulsos mais profundos, ao nível do inconsciente individual e coletivo, o autor orienta que o trabalho precisa levar em consideração ao menos três camadas ou níveis. E o método de análise pautado na semiótica como definida por de Charles Sanders Peirce, esse método parte de uma interpretação dos fenômenos culturais como sistemas de signos, fenômenos 
comunicativos, Peirce sustenta que um signo sempre dará origem a outro signo da mesma forma que um pensamento origina outro, as capacidades dos signos é praticamente ilimitada, podendo representar um objeto material ou imaginário, com a única exigência de que para ser um signo, ele deverá representar outra coisa, pois um signo deve ser algo distinto do seu objeto.

\section{RESULTADOS E/OU DISCUSSÃO (ou Análise e discussão dos resultados)}

Na edição lançada em Lisboa pelo editor Jorge Rodriguez em 1605, duas pequenas gravuras já acompanhavam o texto cervantino, o autor das ilustrações não é conhecido, mas esta é possivelmente a primeira edição do D. Quixote a contar com ilustrações, desde então centenas de edições do texto ganharam as mais variadas interpretações visuais, todas de incontestável valor histórico e artístico. "O cavaleiro da triste figura" metamorfoseou-se ao longo dos séculos, sua imagem acompanhou as transformações do espírito de cada época em que foi ilustrado, entre elas as gravuras produzidas pelo ilustrador francês oitocentista Gustave Doré alcançaram uma espécie de padrão visual para os elementos narrativos das aventuras quixotescas, uma espécie de cânone visual sobre a obra.

$\mathrm{Na}$ análise aqui empreendida, entre as duas representações, observamos que o ilustrador propõe um enfoque idealista sobre a personagem D. Quixote, que em seus traços abandona sua comicidade, torna-se solene e ilustre, na cena onde D. Quixote sagra-se cavaleiro, a narração cervantina é carregada de elementos de comicidade, D. quixote é enganado ao chegar em uma hospedaria que pensa ser um castelo, em seu ritual é diversas vezes atrapalhado por arreios que vinha dar agua aos animais, e acaba jogando as armas de D. Quixote no chão, quebrando todo o clima de sacralidade do evento, ao final D. Quixote sagra-se cavaleiro recebendo golpes e bordoadas, além de ser armado por duas prostitutas, já na narrativa visual (Imagem 1) Doré mantém todo o clima sacro da cerimônia na arrumação das armas, no espaço, que apesar de ser o pátio da hospedaria plenamente iluminado pelo luar, e sobretudo na postura da personagem, uma postura ereta, imponente, em uma pose simétrica entre a personagem e os elementos que compõem a cena, o objetivo do ilustrador parece ser o de representar um d. Quixote heroico, idealizado, enquanto a representação cervantina o próprio D. Quixote é grotesco, alto, magro, desdentado, mal arranjado, "no texto de Cervantes, o que é grotesco vem exatamente das situações em que a grandeza e a dignidade são anuladas: o heroico cavaleiro é, na verdade, um pobre desdentado" (LINARDI, 2007, p. 359).

O cômico e o burlesco no traço de Gustave Doré foi reservado à personagem Sancho Pança, quase sempre representado em uma situação constrangedora, na gravura em que é apresentado, Sancho é colocado em uma relação de disparidade evidente em relação a D. Quixote, o ambiente o contraste entre a pose esguia imponente de D. quixote que enfaticamente gesticula no ar estendendo a figura por mais de dois terços do espaço da gravura, contrasta com a pequenez de um Sancho, encolhido, vacilante, as mãos untas em direção ao chão, a figura ocupa um espaço menor na composição, rodeado de crianças e animais domésticos, aproxima-se de figura do camponês, os 
elementos ligados ao mundo rural emolduram toda a imagem, os porcos, galinhas, o burrinho, a vassoura, o cesto, conformam um imagem de diferença entre o fidalgo cavaleiro e o desajeitado camponês. Características marcantes de Sancho presentes no texto cervantino são apagadas, como as suas ambições, e o senso de praticidade.

Outra característica marcante é a ilustração segundo uma perspectiva realista da obra, observamos que na famosa cena da arremetida de D. Quixote contra os desaforados gigantes a ação é lustrada por Doré, segundo uma visão que não é a da personagem, ao invés disso a ilustração segue uma visão realista de que os gigantes são apenas moinhos de vento, apagando assim as criações fantasiosa mente de D. Quixote, o mesmo se dá na batalha contra os carneiros, onde para D. Quixote trata-se de dois grandes exércitos a se enfrentar, e onde a personagem passa elencar as insígnias, armaduras, escudos e razões dos cavaleiros em batalha, Doré representa os apenas como nos informa a visão de Sancho Pança, apenas carneiros e ovelhas.

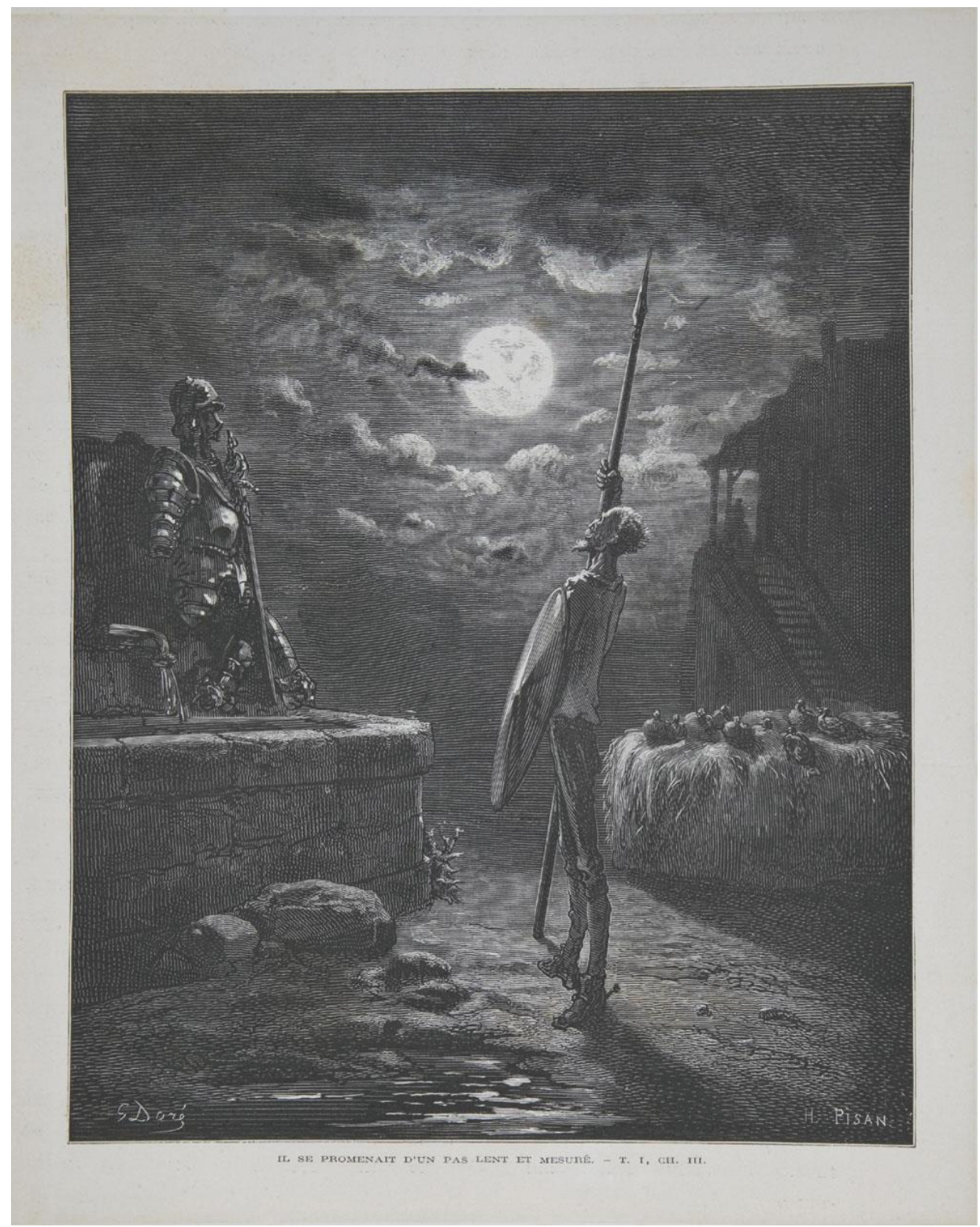

Imagem 1: Il se jette a travers l'escadron des brebis. - T. I, ch. 18. Gustave Doré, H. Pisan 1863, Paris, L'ingénieux hidalgo Don Quichotte de la Manche. Museo Casa Natal de Cervantes (Alcalá de Henares). 


\section{CONSIDERAÇÕES FINAIS}

Durante as investigações podemos inferir que O ilustrador francês Gustave Doré, em sua produção visual para ilustrar o D. Quixote, obra de Miguel de Cervantes, trabalha as personagens representadas de modo bastante unilateral criando uma maneira de ver a obra baseada no realismo, postura que pode ser entendida levando se em consideração uma certa leitura romântica oitocentista do texto cervantino, que orienta o leitor a compreender a personagem de forma idealizada, a interpretação de Doré não é desprovida de fantasia mas o fantástico surge nas ilustrações, apenas quando visa demonstrar a mente da personagem, mas quando é a ação que é representada ela é sempre vista pelos olhos da razão.

As ilustrações centram-se ainda quase que exclusivamente nas duas personagens principais legando pouco ou nenhum espaço para personagens secundárias como Dulcinea del Toboso, Doroteia, Cardênio, o Padre, cujas presenças são muito exploradas por Cervantes.

Percebemos que os efeitos dessas posturas do ilustrador em sua produção visual para o D. Quixote, por suas características realísticas, sua emolduração da personagem na postura heroica, e o seu posterior entendimento como um cânone visual acerca da obra, ajudaram a construir e consolidar uma dimensão trágica para o Quixote que certamente é uma das múltiplas possibilidades de interpretações para o texto cervantino, mas que talvez crie uma certa distância com aquilo que Miguel de Cervantes coloca como objetivo primeiro de sua obra na introdução do Engenhoso fidalgo D. Quixote de La Mancha "divertir e fazer rir".

\section{REFERÊNCIAS}

BURKE, Peter. Testemunha ocular: o uso de imagens como evidência histórica. São Paulo: Editora Unesp, 2017.

CERVANTES, M. de. O engenhoso fidalgo d. Quixote de La Mancha: Primeiro livro. Tradução de Sérgio Molina. São Paulo: 34, 2002.

CHARTIER, Roger. A História cultural: entre práticas e representações. Lisboa: Difel, 1989.

LINARDI, A. B. A. Dom Quixote, Doré e Dalí: As relações entre literatura e pintura. III Encontro de História da Arte, n. 3, Campinas, 2007, pp. 356-365.

MANGUEL, Alberto. Lendo imagens: uma história de amor e ódio São Paulo: Companhia das Letras, 2001.

PANOFSKY, E. Iconografia e Iconologia: Uma introdução ao estudo da arte da Renascença. In: Significado nas artes visuais. Tradução de Maria Clara F. Kneese e J. Guinsburg. São Paulo: Perspectiva, 1991, pp. 47-87.

PEIRCE, Charles Sanders. Semiótica. 4 ed. São Paulo: Perspectiva. 2010. 